www.nature.com/pj

\title{
All-cellulose composite and nanocomposite made from partially dissolved micro- and nanofibers of canola straw
}

\author{
Hossein Yousefi ${ }^{1,2}$, Mehdi Faezipour ${ }^{1}$, Takashi Nishino ${ }^{2}$, Alireza Shakeri ${ }^{3}$ and Ghanbar Ebrahimi ${ }^{1}$ \\ All-cellulose composite (ACC) and nanocomposite (ACNC) were, respectively, made from microfiber and grinding-based nanofiber \\ of canola straw by using a partial dissolution method with the solvent $N, N$-dimethylacetamide/lithium chloride (DMAc/LiCl). The \\ dissolution times were 5, 10, 20, 30,60 and 120 mins. The resultant composites were compared with neat micro-and nanofiber \\ sheets. The average diameter of microfiber was $26 \mu \mathrm{m}$, which was downsized to $32 \mathrm{~nm}$ after grinding. The grinding process is a \\ simple, cheap and fast downsizing method that could reduce fiber diameter by almost three orders of magnitude. The tensile \\ strength of the nanofiber sheet was 11 times higher than that of the microfiber sheet. As dissolution time increased, the amount \\ of non-crystalline matrix in the ACC and ACNC increased, and the apparent crystallinity decreased. The ACC had a tensile \\ strength of $59 \mathrm{MPa}$ when the dissolution time was $120 \mathrm{~min}$, whereas the ACNC approached a maximum tensile strength of \\ $164 \mathrm{MPa}$ after a short dissolution time $(10 \mathrm{~min})$. Fiber pull-out was observed in the tensile-broken surfaces of the micro- and \\ nanofiber sheets, and fibers tended to break when the dissolution time was long.
}

Polymer Journal (2011) 43, 559-564; doi:10.1038/pj.2011.31; published online 20 April 2011

Keywords: All-cellulose nanocomposite; cellulose nanofiber; mechanical properties

\section{INTRODUCTION}

Cellulosic composites are the focus of a current trend toward environmentally friendly composites. ${ }^{1,2}$ All-cellulose composite (ACC) and nanocomposite (ACNC) have been studied for about a decade. $^{3}$ This class of biocomposites is manufactured from cellulose, which functions as both reinforcement and matrix. The matrix and reinforcement phases of this biocomposite are completely compatible with each other, allowing efficient stress transfer and adhesion at their interface. The mechanical properties of such composites can exceed those of glass-fiber composites. ${ }^{3-12}$ Different solvents have been used to make ACC and ACNC, including $\mathrm{N}, \mathrm{N}$-dimethylacetamide/lithium chloride (DMAc/LiCl), ${ }^{3,4,6,7}$ ionic liquid ${ }^{8}$ and sodium hydroxide $(\mathrm{NaOH}) /$ urea. $^{9}$ DMAc/LiCl is especially popular because of its ability to dissolve cellulose under moderate conditions. Moreover, different cellulosic micro- and nanofibers have been used to make ACC and ACNC, including ramie fibers, ${ }^{3,10}$ microcrystalline cellulose, ${ }^{4}$ filter paper, ${ }^{6,8}$ bacterial cellulose, ${ }^{7}$ commercial microfibrillated cellulose, ${ }^{8,12}$ cellulose nanowhisker ${ }^{9}$ and beech pulp. ${ }^{11}$

In this study, cellulose nanofiber produced by grinding was used to make ACNC. This method is in contrast to previous studies that made ACNC from bacterial cellulose and cellulose nanowhiskers. ${ }^{7,9}$ Cellulose nanofibers produced by grinding are fundamentally different from cellulose nanowhiskers as used by Qi et al. ${ }^{9}$ in terms of their entanglement, morphology, production process and yield. ${ }^{13,14}$
In particular, the difference in entanglement can be attributed to the difference between the aspect ratios of cellulose nanowhiskers and of cellulose nanofibers produced by grinding. Grinding is simpler, cheaper and faster than acid hydrolysis, bacterial synthesis or electrospinning, and it is a one-step high-yield process. ${ }^{13,14}$ For instance, we produced all of the nanofibers for this study $(100 \mathrm{~g})$ from bleached cellulose microfibers after just $4 \mathrm{~h}$ in the laboratory. In contrast, the production of cellulose nanowhiskers is costly and time consuming, and involves processes such as acid hydrolysis, centrifuging and dialysis.

The micro- and nanofibers for this research were derived from canola straw, which is an agricultural residue. Large quantities (3 tons per hectare) of canola straw typically remain as waste after the harvest, and the straw is burnt or ploughed into the ground. ${ }^{15}$ Thus, it is worth trying to convert such agricultural waste into high-performance materials. The average length and diameter of canola straw fibers are 1215 and $28 \mu \mathrm{m}$, respectively, which is in the same range as hardwood fibers. ${ }^{15}$ The main components of canola straw are cellulose, lignin, extractives, and ash, which make up 43,17, 12 and $6 \%$ of the contents, respectively. ${ }^{16}$ Ours is the first study to use microfibers and nanofibers from the same starting material (canola straw) to manufacture ACC and ACNC. Using the same material to make both ACC and ACNC provides an opportunity to evaluate the effect of dissolution time on micro- and nanoscale materials and the resultant

${ }^{1}$ Department of Wood and Paper Science and Technology, Faculty of Natural Resources, University of Tehran, Karaj, Iran; ${ }^{2}$ Department of Chemical Science and Engineering, Graduate School of Engineering, Kobe University, Kobe, Japan and ${ }^{3}$ Department of Chemistry, Golestan University, Gorgan, Iran

Correspondence: Dr H Yousefi, Department of Wood and Paper Science and Technology, Faculty of Natural Resources, University of Tehran, Karaj 31585-4314, Iran. E-mail: yousefi329@gmail.com

Received 26 November 2010; revised 7 March 2011; accepted 8 March 2011; published online 20 April 2011 
properties of the ACC and ACNC produced. Our first objective was to investigate the effect of downsizing cellulose microfibers by grinding on the properties of microfiber and nanofiber sheets (the starting materials for ACC and ACNC). Our second objective was to evaluate the effect of dissolution times on micro- and nanoscale cellulose fibers and characterize the resultant ACC and ACNC.

\section{EXPERIMENTAL PROCEDURE}

\section{Materials}

Canola straw was obtained from canola fields in Karaj, Iran. $\mathrm{NaOH}$, hydrogen peroxide, sodium chlorite and anthraquinone were obtained from Merck and Co. Inc., Darmstadt, Germany. Chlorine dioxide $\left(\mathrm{ClO}_{2}\right)$ was prepared in the laboratory using sodium chlorite and chlorine. DMAc and $\mathrm{LiCl}$ were obtained from Nacalai Tesque, Kyoto, Japan.

\section{Pulping and bleaching}

Canola straw was cut and chopped by a Pallman chopper (Pallman, Zweibrücken, Germany) and then depithed by screening. The ratio of the pith to the whole stalk of canola was $5.6 \mathrm{wt} \% .{ }^{15}$ De-pithed canola straw was cooked in a digester with $\mathrm{NaOH}$ and anthraquinone under the conditions shown in Table 1. The pulped fibers were bleached in three stages, and potassium hydroxide aqueous solution $(10 \mathrm{wt} \%)$ was used to cleave hemicelluloses.

The alpha-cellulose content of the microfibers was determined based on the TAPPI T $429 \mathrm{~cm}-84$ standard. To $0.3 \mathrm{~g}$ (dry weight) of microfibers, $20 \mathrm{ml}$ of $17.5 \% \mathrm{NaOH}$ was added and the mixture was let to stand for $10 \mathrm{~min}$. Distilled water $(33 \mathrm{ml})$ was then added to dilute the $\mathrm{NaOH}$ concentration to $7.3 \%$. After stirring the mixture for $1 \mathrm{~h}$, the cellulose fraction was collected by filtering and was determined from the weight change. This procedure was repeated three times, and the amount of alpha-cellulose was averaged.

The water slurry with $1 \mathrm{wt} \%$ canola straw fibers was passed once through a grinder (MKCA6-3; Masuko Sangyo, Kawaguchi, Japan) at 1500 r.p.m. The well-dispersed suspension $(0.2 \mathrm{wt} \%)$ of canola nanofibers was filtered by vacuuming to make nanofiber sheet, followed by drying at ambient temperature. Next, the nanofiber sheet was hot pressed at $100^{\circ} \mathrm{C}$ and $2 \mathrm{MPa}$ for $1 \mathrm{~h}$. This process resulted in nanofiber sheets (nanopaper). Microfiber sheets (micropaper) were also prepared from bleached microfibers under the same conditions. Micro- and nanopaper were used as starting materials for making ACC and ACNC, respectively.

\section{Preparation of ACC and ACNC}

Micro- and nanopaper were activated by immersing them in distilled water, acetone and DMAc for $2 \mathrm{~h}$ each at room temperature. Each activated sheet was then immersed in $\mathrm{DMAc} / \mathrm{LiCl}(8 \% \mathrm{LiCl})$ for six dissolution times ranging from 5 to $120 \mathrm{~min}$ at room temperature. The sheets were then immersed in methanol for $12 \mathrm{~h}$ followed by drying under reduced pressure. The thicknesses of the ACC and ACNC ranged from 40 to $120 \mu \mathrm{m}$. Hereafter, the individual ACC and ACNC samples will be denoted by their dissolution times; for example, those prepared with a dissolution time of 5 min will be called ACC-5 and ACNC-5, respectively. The samples were stored in a climate chamber at $60 \pm 2 \%$ relative humidity and $25^{\circ} \mathrm{C}$ before each test.

Figure 1 shows a schematic outline of the preparation of ACC and ACNC from canola straw.

\section{Measurements}

X-ray diffraction photographs were recorded on an imaging plate with a camera length of $37.5 \mathrm{~mm}$. The specimens were irradiated by $\mathrm{Cu} \mathrm{K} \alpha$ radiation from a Rigaku RINT-2000 at $40 \mathrm{kV}$ and $20 \mathrm{~mA}$ from directions perpendicular and parallel to the sample surface. The diffraction profile was detected using an X-ray goniometer with a symmetric reflection geometry in the range of $2 \theta=10^{\circ}-40^{\circ}$ at a scanning speed of $1.2^{\circ} \mathrm{min}^{-1}$.

Crystallinity index (CrI) was evaluated using the following equation (1): ${ }^{17}$

$$
\mathrm{CrI}=100\left(I-I_{\beta}\right) / I
$$

where $I$ is the diffraction intensity assigned to the 200 reflection of cellulose $I_{\beta}$, which is typically in the range $2 \theta=21^{\circ}-23^{\circ} . I_{\beta}$ is the intensity measured at $2 \theta=18^{\circ}$, where the maximum occurs in a diffractogram for non-crystalline cellulose.

The crystallite size of cellulose was estimated by Scherrer's equation (2): ${ }^{18}$

$$
D=\lambda / \beta \cos \theta
$$

where $D$ is the crystallite size, $\lambda$ is the $\mathrm{X}$-ray wavelength $(0.15418 \mathrm{~nm}), \theta$ is the diffraction angle for the (200) plane and $\beta$ is the corrected integral width.

The crystallite orientation $(\pi)$ was determined by the following equation (3) for the azimuthal profile of the 200 reflection: ${ }^{18}$

$$
\pi=180-H / 180
$$

where $H$ is the full width at the half maximum along the Debye-Scherrer ring.

The aqueous suspension of nanofibers was diluted with 10 times its volume of methanol, and a thin layer of nanofiber was deposited onto the silicon substrate. All specimens were dried in vacuum and coated with platinum/ palladium. The specimens were observed with field emission scanning electron microscopy (JSM-6700F; JEOL, Tokyo, Japan) at an accelerating voltage of $5 \mathrm{kV}$. The diameters of 300 micro- and nanofibers were measured on field emission scanning electron microscopy micrographs using AutoCAD software (Autodesk, San Rafael, CA, USA). The broken surfaces of the ACC and ACNC samples after the tensile tests were also observed.

The stress-strain curves of the ACC and ACNC were measured using a tensile tester (Autograph AGS, Shimadzu, Tokyo, Japan) at room temperature. The specimens were $20 \mathrm{~mm}$ long and $4 \mathrm{~mm}$ wide. The load cell and extension rate were $1000 \mathrm{~N}$ and $1 \mathrm{~mm} \mathrm{~min}^{-1}$, respectively. We calculated the average values for the tensile strength $\left(o_{\max }^{\prime}\right)$, Young's modulus $(E)$ and strain at break $\left(\varepsilon_{\max }\right)$ of eight specimens. On each graph bar, $95 \%$ confidence intervals are shown to indicate the differences in means.

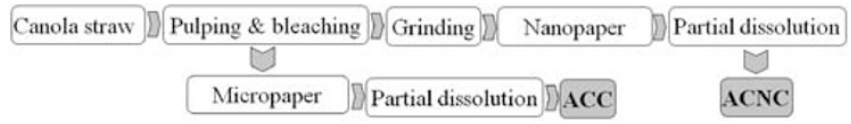

Figure 1 Schematic diagram for preparing all-cellulose composite (ACC) and

\begin{tabular}{|c|c|c|c|c|c|}
\hline \multirow[b]{2}{*}{ Stage } & \multirow[b]{2}{*}{ Pulping } & \multicolumn{3}{|c|}{ Bleaching } & \multirow[b]{2}{*}{ Removing hemicelluloses } \\
\hline & & Step 1 & Step 2 & Step 3 & \\
\hline Chemical charge (wt\%) & $\mathrm{NaOH}(22) \mathrm{AQ}^{\mathrm{a}}(0.1)$ & $\mathrm{ClO}_{2}(2)$ & $\mathrm{NaOH}(2) \mathrm{H}_{2} \mathrm{O}_{2}(2-3)$ & $\mathrm{ClO}_{2}(1)$ & $\mathrm{KOH}(10)$ \\
\hline Pulp consistency (wt\%) & 17 & 10 & 10 & 10 & 10 \\
\hline Temperature $\left({ }^{\circ} \mathrm{C}\right)$ & 170 & 60 & 70 & 80 & 80 \\
\hline Time (h) & 3 & 1 & 1 & 2 & 2 \\
\hline
\end{tabular}
nanocomposite (ACNC) from canola straw.

Table 1 Pulping and bleaching conditions of canola straw

Abbreviations: $\mathrm{AQ}$, anthraquinone; $\mathrm{ClO}_{2}$, chlorine dioxide; $\mathrm{H}_{2} \mathrm{O}_{2}$, hydrogen peroxide; $\mathrm{KOH}$, potassium hydroxide; $\mathrm{NaOH}$, sodium hydroxide

${ }^{a}$ Anthraquinone. 


\section{RESULTS AND DISCUSSION}

Micropaper and nanopaper

After pulping and bleaching, the cellulose content of canola straw fibers reached $92 \pm 3 \%$. The purifying process used in this study can successfully produce high-quality cellulose.

Figure 2 shows field emission scanning electron microscopy micrographs of (a) canola straw microfiber after pulping and bleaching and (b) nanofibers after grinding. The diameter distributions of canola straw fibers before and after grinding are shown in Figures $2 \mathrm{c}$ and $\mathrm{d}$, respectively. The microfibers ranged from 10 to $60 \mu \mathrm{m}$ in diameter (average: $26 \pm 9 \mu \mathrm{m}$ ). The microfibers were downsized into nanofibers with diameters ranging from 5 to $80 \mathrm{~nm}$ (average: $32 \pm 10 \mathrm{~nm}$ ) as a result of the pressure and shearing stresses created between the grinding stones. Not only did the fiber diameter decrease markedly but the diameter distribution also became narrower.

Figure 3 shows the stress-strain curves of micro- and nanopaper derived from canola straw. It is clear that the mechanical properties of nanopaper are markedly improved compared with those of micropaper. Values for $o_{\max }^{\prime}, E$ and $\varepsilon_{\max }$ of nanopaper were $114 \mathrm{MPa}$, $13.6 \mathrm{GPa}$ and $5.7 \%$, respectively. These values were 990, 540 and $335 \%$ higher than those of micropaper, respectively. Microfibers possess many defect points, such as fiber lumen and pits. These defects can cause stress concentrations under a tensile load, which results in poor mechanical properties. Grinding diminished the number of defect points. Furthermore, as the fiber diameter decreased to the nanoscale, the specific surface area, quantity of hydrogen bonds and fiber entanglement increased. Therefore, the nanopaper got a unique structure, and its mechanical properties were superior to those of the micropaper. ${ }^{19,20}$

\section{ACC and ACNC}

Figure 4 shows the X-ray diffraction profiles of (a) ACC and (b) ACNC, together with those of micropaper and nanopaper. The diffraction profiles of the micropaper and nanopaper showed typical peaks at $2 \theta=15.2^{\circ}, 16.1^{\circ}, 22.6^{\circ}$ and $34.5^{\circ}$ of cellulose $I_{\beta}$. As the dissolution time increased, the non-crystalline scattering apparently increased, which appeared as a broad scattering around $2 \theta=18^{\circ}$. This indicates that the dissolution of cellulose fibers progressed gradually with time, and the resolidified portions mainly converted to noncrystalline regions in the ACC and ACNC. ${ }^{6,21}$

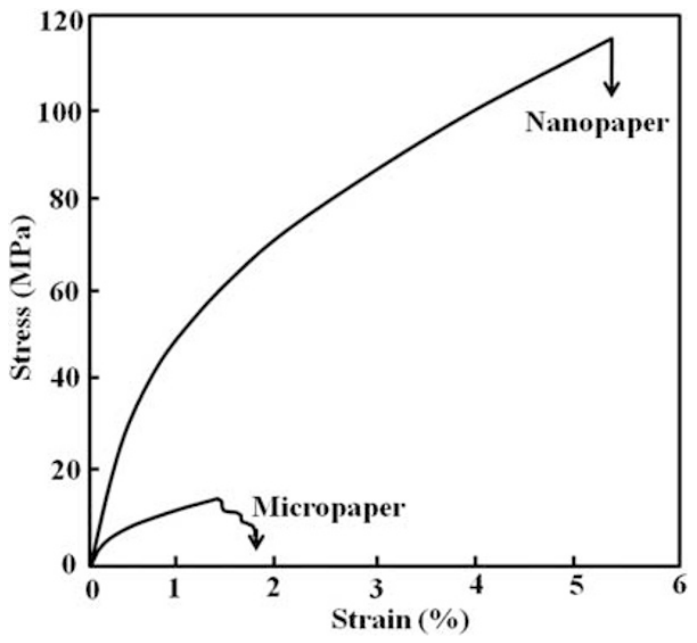

Figure 3 Stress-strain curves of micro- and nanopaper of canola straw.
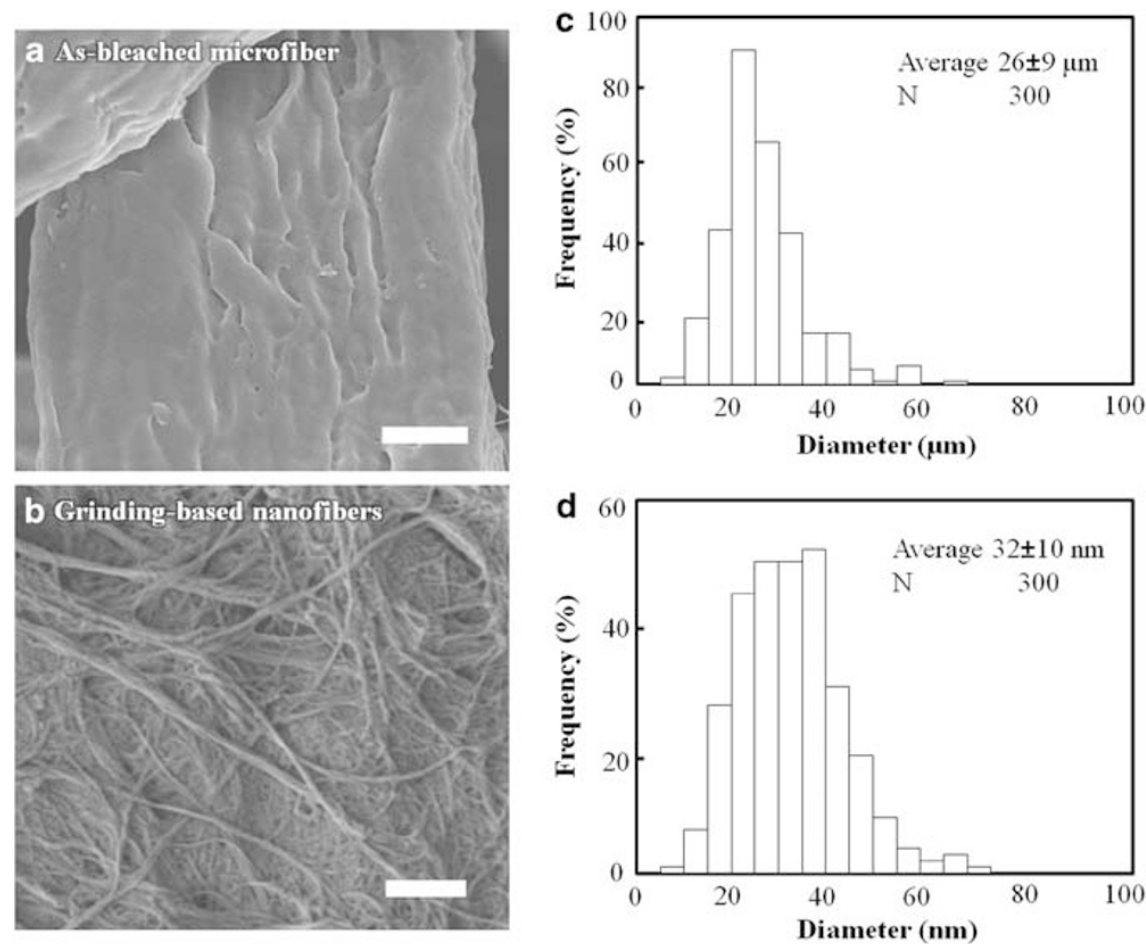

Figure 2 Field emission scanning electron microscopy micrographs of (a) the original microfiber of canola straw (scale bar is $2 \mu \mathrm{m}$ ) and (b) nanofibers produced by grinding (scale bar is $500 \mathrm{~nm}$ ). Diameter distribution of (c) microfibers and (d) nanofibers. The average diameter and number of measured micro- and nanofibers are on $\mathbf{b}$ and $\mathbf{d}$. 

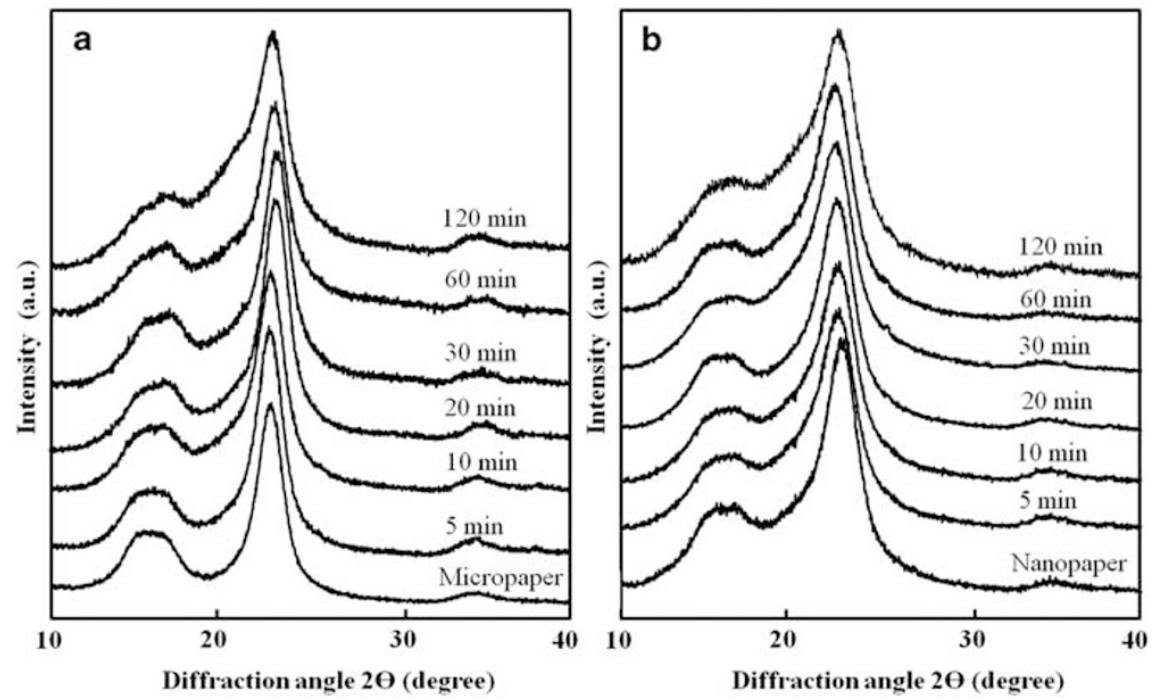

Figure 4 X-ray diffraction profiles of (a) micropaper of canola straw and all-cellulose composite (ACC), and (b) nanopaper of canola straw and all-cellulose nanocomposite (ACNC).

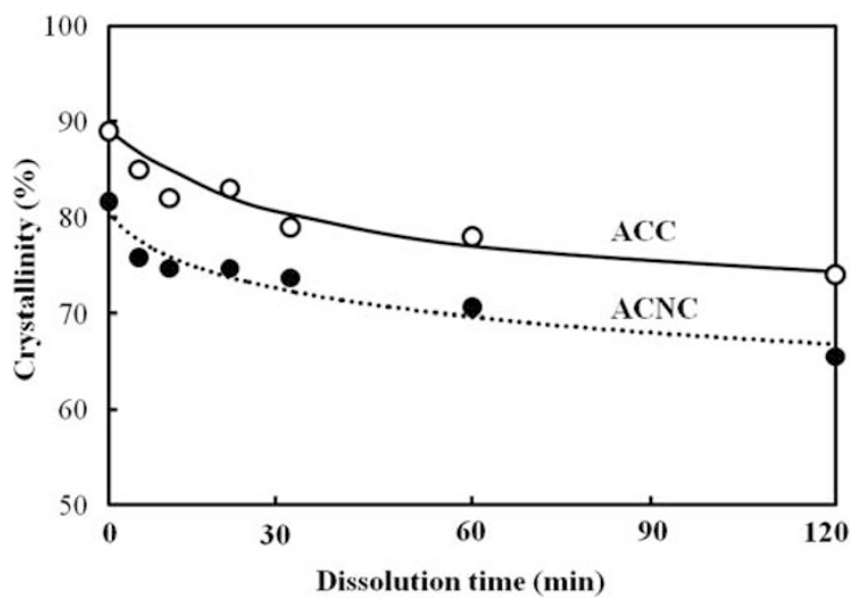

Figure 5 Effect of dissolution time on apparent crystallinity of all-cellulose composite (ACC) and nanocomposite (ACNC).

Figure 5 shows the effect of dissolution time on the apparent crystallinity of ACC and ACNC. As dissolution time increased, the apparent crystallinity of ACC and ACNC declined. The loss of crystallinity may be related to the fact that, as dissolution time increases, a larger amount of solvent penetrates the gap between the crystallites and dissolves the amorphous and outer chains of the crystallites. On the basis of the decrease in crystallinity, it is possible to estimate the amount of cellulose recovered as solid after the partial dissolution. For example, $7 \%$ of the crystalline regions were recovered as matrix with a dissolution time of $10 \mathrm{~min}$.

The crystal size of microfiber sheet, nanofiber sheet, ACC-120 and ACNC- 120 was $5.5,5.1,5$ and $4.5 \mathrm{~nm}$, respectively. The crystallite size of grinding-based nanofiber was lower than that of microfiber, which was a result of the high shear and pressure forces during grinding. The crystallite size of ACC and ACNC also decreased compared with that of the starting materials, which can be a sign that solvent penetrated into the gaps between crystals and dissolved their outer cellulose chains.

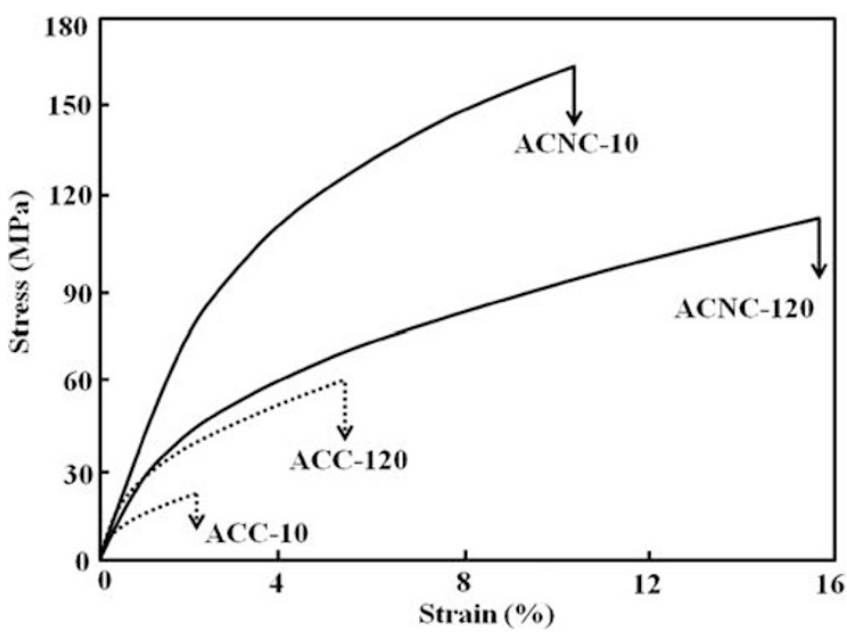

Figure 6 Stress-strain curves of all-cellulose composite (ACC) and nanocomposite (ACNC) prepared with different dissolution times.

Figure 6 shows typical stress-strain curves of ACC and ACNC for dissolution times of 10 and $120 \mathrm{~min}$. ACNC had stronger mechanical properties compared with ACC. By comparing ACC and ACNC at the same dissolution times, we inferred that the solvent could effectively dissolve the nanofibers and that the surface of the nanofibers was converted into an adequate matrix phase for cementing adjacent nanofibers. In previous studies using microfibers to make ACC, the tensile strength approached $211 \mathrm{MPa}$ after a dissolution time of $12 \mathrm{~h}^{4}$ and $158 \mathrm{MPa}$ after a dissolution time of $10 \mathrm{~h} .{ }^{9}$ Thus, it appears that $120 \mathrm{~min}$ is not sufficient to generate an adequate matrix phase in ACC; hence, the mechanical properties could not be adequately improved. The poor characteristics of ACC are also related to the fact that the microfibers have more defect points and a lower specific surface area compared with the nanofibers.

Figure 7 shows the effect of varying dissolution time on the mechanical properties of ACC and ACNC, including (a) $o_{\max }^{\prime}$, (b) $E$ and (c) $\varepsilon_{\max }$. As the dissolution time increased, $o_{\max }^{\prime} E$ and $\varepsilon_{\max }$ of 

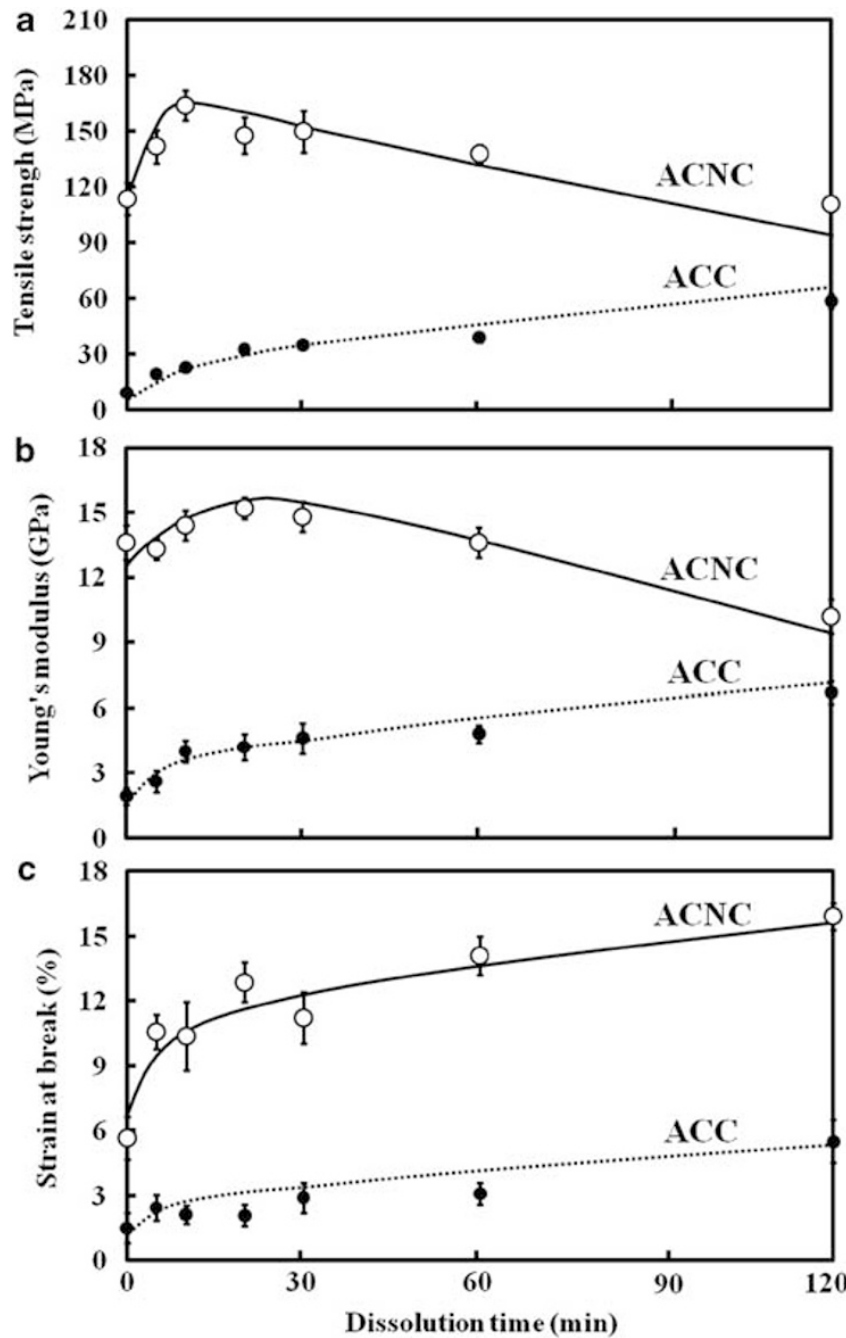

Figure 7 Effect of dissolution time on the mechanical properties of allcellulose composite (ACC) and nanocomposite (ACNC). (a) Tensile strength, (b) Young's modulus and (c) strain at break.

ACC increased significantly, reaching $59 \mathrm{MPa}, 6.7 \mathrm{GPa}$ and $5.5 \%$ after a dissolution time of $120 \mathrm{~min}$. By contrast, the highest $o_{\max }^{\prime}(164 \mathrm{MPa})$ and $E(15.2 \mathrm{GPa})$ for ACNC were attained after the shorter dissolution times of 10 and $20 \mathrm{~min}$, and $o_{\max }^{\prime}$ and $E$ fell at longer dissolution times. As dissolution time increased, the amorphous regions and the outer layers of crystallites were dissolved and converted to non-crystalline regions. The resolidified non-crystalline parts had the role of the matrix phase, filling micro- and nanovoids, encapsulating the nanofiber surfaces and cementing adjacent nanofibers. Because the matrix and the reinforcement were cellulose, an effective interphase could be formed, and the composite tended to have an interface-free structure. Therefore, stress was adequately transferred between the matrix and the reinforcement, and this resulted in superior mechanical properties. $^{3,6-8}$ In the case of ACNC, after 30 to 120 min of dissolution, more crystallites turned into non-crystalline cellulose. That is, the amount of reinforcement decreased; hence, the residual undissolved nanofibers were not sufficient to reinforce the composite.

As seen in Figure $7 \mathrm{c}$, the $\varepsilon_{\max }$ of both ACC and ACNC increased (that is, plastic deformation increased) as dissolution time increased. This trend can be attributed to the fact that, over longer dissolution periods, the ACC and ACNC sheets became swollen, leading to a significant reduction in the degree of interplanar hydrogen bonding. The decline in hydrogen bonds allowed slippage to occur between the nanofiber planar layers, and it resulted in a considerable increase in the strain at break of the ACNC. ${ }^{7}$ These results are consistent with the previous literature. ${ }^{7,8}$

As demonstrated above, micropaper had the weakest properties, and ACNC-10 had the strongest. These results imply that we could fabricate a nanocomposite with a tensile strength 17 times that of micropaper using two-step process of grinding and $10 \mathrm{~min}$ partial dissolution.

Figure 8 shows the broken surfaces of (a) micropaper, (b) ACC-120, (c) nanopaper and (d) ACNC-120 together with the X-ray diffraction photographs perpendicular to the surface. Fiber pull-out under tensile load was observed in the micro- and nanopaper, which means there was not a strong interfiber interaction for these specimens. Fiber pullout was also observed for ACC-120 because the fiber-fiber and fibermatrix interactions were not strong enough. However, in the case of ACNC-120, a tensile load caused the nanofibers to break. This indicates that the non-crystalline cellulose made good interfaces by cementing adjacent nanofibers. In addition, as a result of the nanofiber-matrix interaction, stress transfer from the matrix to the undissolved nanofibers fell as the matrix volume fraction increased. ${ }^{22}$ However, the long dissolution time caused a loss of crystallinity; the native strength of the nanofibers decreased and the nanofiber broke when it was loaded. On the basis of what is shown in Figures $8 \mathrm{a}-\mathrm{d}$, we can conclude that a larger volume of matrix was created, and it covered the surface of the nanofibers when it was immersed in the solvent. In addition, ACNC-120 had undissolved nanofiber cores covered with non-crystalline cellulose (Figure $8 \mathrm{~d}$ ). The X-ray diffraction photographs showed clear Debye-Scherrer rings that could be attributed to cellulose $I_{\beta}$ with a perfectly random orientation of crystallites. Although ACC-120 and ACNC-120 had the same dissolution times, the X-ray diffraction photograph of ACNC-120 (Figure 8b) showed more diffuse Debye-Scherrer rings. This result is consistent with the crystallinity loss shown in Figure 6.

Figure 9 shows the X-ray diffraction photographs parallel to the sheet surface and the diffraction intensity distributions for the 200 reflection along the Debye-Scherrer ring of (a) micropaper, (b) ACC120, (c) nanopaper and (d) ACNC-120. These photographs clearly show the sheets' laminate structure. The crystallite orientations $(\pi)$ of the micropaper, ACC-120, nanopaper and ACNC-120 were 68, 61, 58 and $55 \%$, respectively. The lower values of $\pi$ for the ACC and ACNC relative to those of the corresponding micro- and nanopapers had the effect of increasing $\varepsilon_{\max }$.

\section{CONCLUSION}

All-cellulose composite and nanocomposite were made from microand nanofibers of canola straw using different dissolution times. The structure and properties of these fibers were compared with those of micropaper and nanopaper. This study showed that a very low-value agricultural residue could be turned into a highperformance nanocomposite (tensile strength: 164 MPa) through a cheap and fast method of downsizing (grinding) followed by a short partial dissolution time of $10 \mathrm{~min}$. In contrast, ACC required a long dissolution time $(120 \mathrm{~min})$, and the tensile strength of the composite $(59 \mathrm{MPa})$ was only a third of that of the nanocomposite made from nanofibers. Because this ecocomposite is made entirely of cellulose, it can be fully biodegradable and recyclable. Canola straw can now be regarded as a promising low-cost raw material for highperformance composites. 

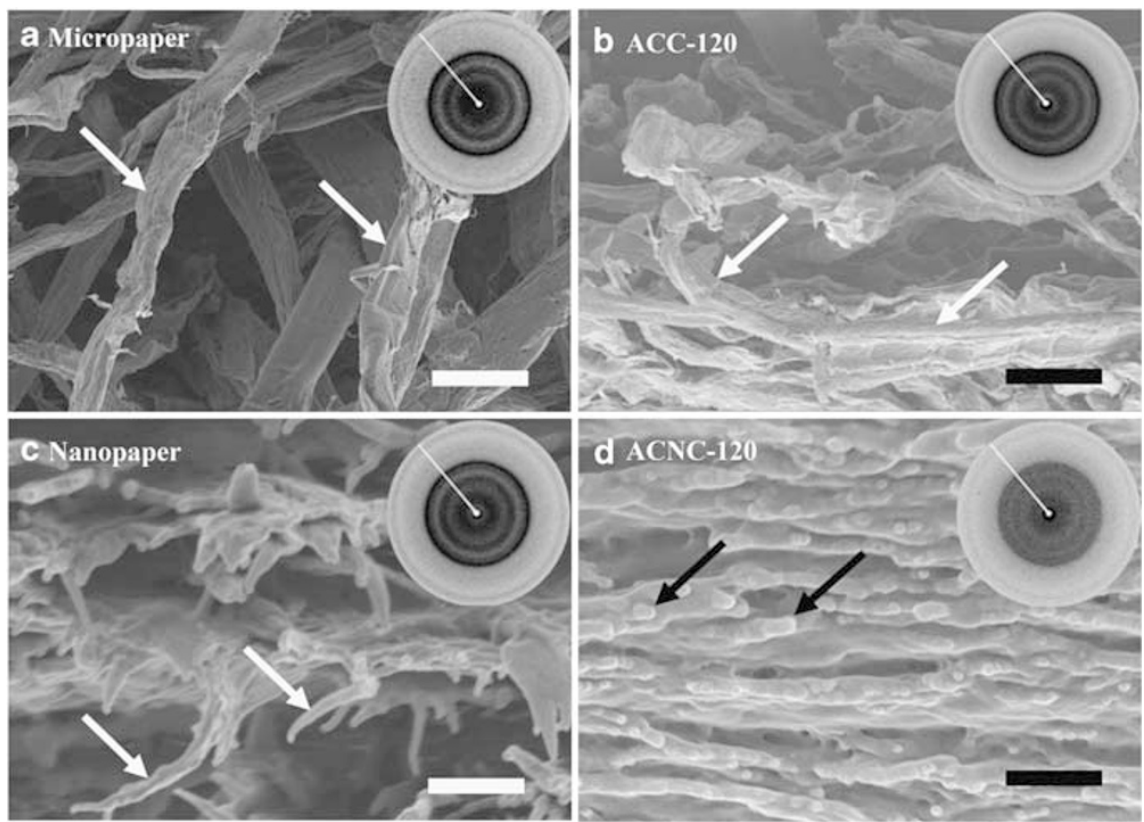

Figure 8 Field emission scanning electron microscopy (FE-SEM) micrographs and X-ray diffraction photographs of the broken surface after tensile testing of (a) micropaper of canola straw, (b) all-cellulose composite (ACC)-120, (c) nanopaper and (d) all-cellulose composite nanocomposite (ACNC)-120. Arrows show the pulled-out micro- and nanofibers in $\mathbf{a}, \mathbf{b}$ and $\mathbf{c}$ and broken nanofiber in $\mathbf{d}$. The scale bars are $20 \mu \mathrm{m}$ (a and b) and $200 \mathrm{~nm}$ (c, d), respectively.
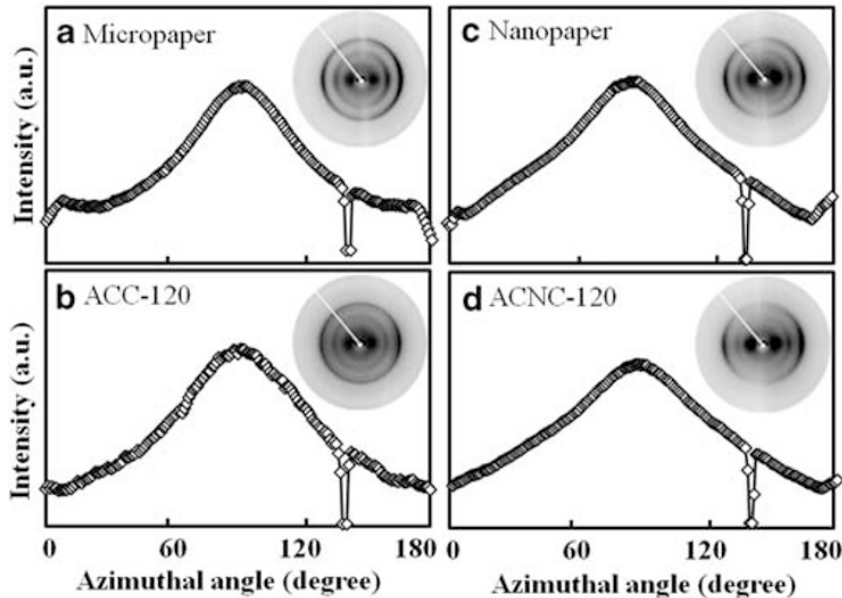

Figure 9 X-ray diffraction photographs and intensity distribution along the Debye-Scherrer ring of (a) micropaper, (b) all-cellulose composite (ACC)120, (c) nanopaper and (d) all-cellulose nanocomposite (ACNC)-120. The spike in intensity results from the shadow of the beam stopper.

\section{ACKNOWLEDGEMENTS}

We would like to thank Dr S Hedjazi and Mr AH Heidari for their help in the pulping and bleaching process. We acknowledge the financial support of a Grant-in-Aid for Scientific Research from the Ministry of Education, Culture, Science, Sports and Technology, Japan (no. 20246100). Special Coordination Funds for Promoting Science and Technology, Creation of Innovation Centers for Advanced Interdisciplinary Research Areas (Innovative Bioproduction Kobe), MEXT, Japan are also acknowledged. HY also thanks the Iranian Ministry of Science for its financial support through a fellowship.

1 Berglund, L. \& Peijs, T. Cellulose biocomposites-from bulk moldings to nanostructured systems. MRS Bull. 35, 201-207 (2010).
2 Eichhorn, S. J., Dufresne, A., Aranguren, M., Marcovich, N. E., Capadona, J. R., Rowan, S. J., Weder, C., Thielemans, W., Roman, M., Renneckar, S., Gindl, W., Veigel, S., Yano, H., Abe, K., Nogi, M., Nakagaito, A. N., Mangalam, A., Simonsen, J., Benight, A. S., Bismarck, A., Berglund, L. A. \& Peijs, T. Current international research into cellulose nanofibres and nanocomposites. J. Mater. Sci. 45, 1-13 (2010).

3 Nishino, T., Matsuda, I. \& Hirao, K. All-cellulose composite. Macromolecules 37, 7683-7687 (2004).

4 Gindl, W. \& Keckes, J. All-cellulose nanocomposite. Polymer 46, 10221-10225 (2005).

5 Duchemin, B. J. C., Newman, R. H. \& Staiger, M. P. Structure-property relationship of all-cellulose composites. Compos. Sci. Tech. 69, 1225-1230 (2009).

6 Nishino, T. \& Arimoto, N. All-cellulose composite by selective dissolving of fiber surface. Biomacromolecules 8, 2712-2716 (2007).

7 Soykeabkaew, N., Chandeep, S., Nishino, T. \& Peijs, T. All-cellulose nanocomposites by surface selective dissolution of bacterial cellulose. Cellulose 16, 435-444 (2009).

8 Duchemin, B. J. C., Mathew, A. \& Oksman, K. All-cellulose composites by partial dissolution in the ionic liquid 1-butyl-3-methylimidazolium chloride. Composites 40, 2031-2037 (2009).

9 Qi, H., Cai, J., Zhang, L. \& Kuga, S. Properties of films composed of cellulose nanowhiskers and a cellulose matrix regenerated from alkali/urea solution. Biomacromolecules 10, 1597-1602 (2009).

10 Soykeabkaew, N., Arimoto, N., Nishino, T. \& Peijs, T. All-cellulose composites by surface selective dissolution of aligned ligno-cellulosic fibres. Compos. Sci. Tech. 68, 2201-2207 (2008)

11 Gindl, W., Schoberl, T. \& Keckes, J. Structure and properties of a pulp fibre-reinforced composite with regenerated cellulose matrix. Appl. Phys. A 83, 19-22 (2006).

12 Yousefi, H., Nishino, T., Faezipour, M., Ebrahimi, G., Shakeri, A. \& Morimone, S. All-cellulose nanocomposite made from nanofibrillated cellulose fibers. Adv. Compos. Lett. 19, 6 (2010).

13 Abe, K., Iwamoto, S. \& Yano, H. Obtaining cellulose nanofibers with a uniform width of $15 \mathrm{~nm}$ from wood. Biomacromolecules 8, 3276-3278 (2007).

14 Yousefi, H., Ebrahimi, G., Mashkour, M. \& Nishino, T. Cellulose nanofiber (CNF) for nanocomposites production: opportunities and challenges. Proceeding of the Sixth International Workshop on Green Composites, Sep. 8-10, 151-154 (Gumi, Korea, 2010)

15 Yousefi, H. Canola straw as a bio-waste resource for medium density fiberboard (MDF) manufacture. Waste Manage. 29, 2644-2648 (2009).

16 Ahmadi, M., Latibari, A. J., Faezipour, M. \& Hedjazi, S. Neutral sulfite semi-chemical pulping of rapeseed residues. Turkish J. Agric. Forest 34, 11-16 (2010).

17 Segal, L., Creely, J., Martin, J. A. \& Conrad, M. An empirical method for estimating the degree of crystallinity of native cellulose using the $\mathrm{X}$-ray diffractometer. Text. Res. J. 29, 786-794 (1959)

18 Kakudo, M. \& Kasai, N. X-ray Diffraction By Polymers (Elsevier: Amsterdam, 1972).

19 Nogi, M., Iwamoto, S., Nakagaito, N. A. \& Yano, H. Optically transparent nanofiber paper. Adv. Mater. 21, 1595-1598 (2009)

20 Henriksson, M., Berglund, L., Isaksson, P., Lindström, T. \& Nishino, T. Cellulose nanopaper structures of high toughness. Biomacromolecules 9, 1579-1585 (2008).

21 Shakeri, A. \& Staiger, M. Phase transformations in regenerated microcrystalline cellulose following dissolution by an ionic liquid. Bioresources 5, 979-989 (2010).

22 Pullawan, T., Wilkinson, A. N. \& Eichhorn, S. J. Discrimination of matrix-fibre interactions in all-cellulose nanocomposites. Compos. Sci. Tech. 70, 2325-2330 (2010). 